\title{
Procedimientos comunes en la comunicación política y en la comunicación empresarial
}

\author{
Dra. Carmen Fernández Camacho \\ Profesora Titular Interina de Relaciones Públicas \\ Universidad de Valladolid
}

\section{RESUMEN}

Las técnicas persuasivas son una realidad que se ha manifestado, como fenómeno comunicativo inherente al hombre, a largo de la historia en múltiples formas: a través de la palabra hablada, de la imagen, de la literatura, los medios impresos, audiovisuales y, en la actualidad, los medios telemáticos. Por otro lado, estas técnicas han sido las mismas en comunicación política y en comunicación empresarial e, incluso, según la eficacia que haya tenido su aplicación en uno de dichos procesos comunicativos, el otro, seguidamente, lo ha ejecutado como aquí demostraremos.

\section{ABSTRACT}

The persuasive techniques are a reality that has been manifested, as communicative phenomenon inherent in the man, to long of the history in multiple forms: across the spoken word, of the image, the literature, mass media and new Web sites. By another way, these techniques have been joined the same in the development of the political and managerial communication and, even, according to the efficiency that has had their application in one of above mentioned communicative process, and the other following it has been executed as we will prove.

Palabras claves: Comunicación/Persuasión/Política/Empresa.

Key words: Communication/Persuasion/Politics/Institution.

\section{Introducción}

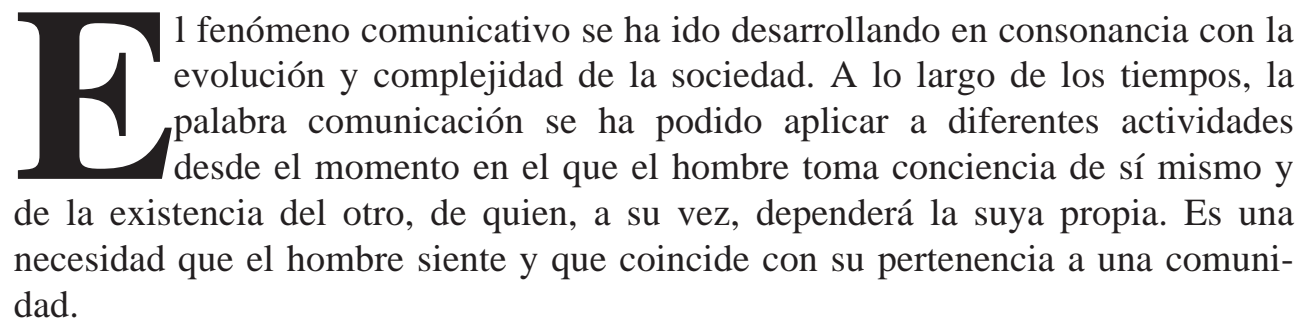


Dentro de estas comunidades, que con el paso del tiempo serán más complejas, el hombre se comunica con los demás en función, principalmente, de la posición que ocupa en un momento determinado y en función de una finalidad, de un objetivo general que es el de obtener la modificación bien de las opiniones, bien de las actitudes negativas de no aceptación, transformándolas en opiniones o actitudes positivas de aceptación o de acción, pero siempre en relación a un objetivo determinado.

Por consiguiente, todos aquellos individuos, grupos u organizaciones que actúan en una determinada sociedad, y con independencia de la calificación que se les atribuya, todos ellos se caracterizan por actuar, de forma consciente o inconsciente, en función de ciertos objetivos, es decir, tratando de conseguir posiciones más o menos definidas en el juego social y, si se quiere, como consecuencia, en el propio juego comunicativo y en la dialéctica social. Dicha afirmación no quiere decir que en muchos casos la comunicación entre individuos no tenga más finalidad que la de encontrarse con otro, diálogo que se produce sólo bajo situaciones igualitarias. Sin embargo, no es éste el campo de investigación que pretendemos determinar, sino aquél en el cual los individuos son o gobernantes o gobernados, vendedores o consumidores, dentro de la sociedad a la que pertenecen.

Cuando los individuos se comunican en función de estos roles sociales, el proceso de comunicación, que entre ellos se genera, se enmarca en un ámbito social. Dentro de este espacio, la tendencia imperante hacia modelos comunicativos totalitarios o democráticos, influida a su vez por factores de cambio social, económico, políticos, culturales e históricos, determina el mayor o menor juego junto con las combinaciones y posiciones relativas de los distintos sistemas de comunicación.

Lógicamente para alcanzar determinados fines, explícitos o implícitos, racionales o irracionales, los miembros que conforman la sociedad utilizan una serie de recursos en función de sus posibilidades e imaginación. Dentro de estos recursos son fundamentales, los de carácter comunicativo conocidos con diferentes nombres como información, publicidad, propaganda, relaciones públicas o publicity, instrumentos, en definitiva, que se utilizan para conseguir los objetivos previamente determinados. Estos instrumentos se han ido perfeccionando a lo largo de la historia según las necesidades sociales, políticas o económicas de los hombres. Ninguno de los instrumentos de comunicación que el ser humano ha ido creando a lo largo de la historia ha excluido a los anteriores, únicamente les ha restado cierto protagonismo el nacimiento de medios más perfectos y de mayor alcance combinándose unos y otros con el objetivo de transmitir sus mensajes y alcanzar con ello sus fines.

Ya en las civilizaciones más primitivas se observa la pretensión de divulgar información con el objetivo de influir en las acciones de los individuos. Virgilio, 
en las Geórgicas, intenta persuadir a la población urbana para que se desplace a las granjas y contribuya a la producción de alimentos. Demóstenes utiliza la publicidad para oponerse a los proyectos de Felipe de Macedonia cubriendo con pancartas políticas las murallas de Pompeya y César, mediante envíos de informes a Roma sobre su éxito como gobernador de la Galia, incita a los romanos en busca de apoyo para atravesar, en el 50 a. J., el Rubicón ${ }^{1}$. Ninguno de los que ejercieron el poder dio la espalda a los juicios y reacciones de sus súbditos, ni el más autoritario de los gobernantes ha ignorando a la población ${ }^{2}$.

Pero, el hombre desde sus inicios busca también otro bienestar y no sólo aquél que pueda aportarle el mundo de las creencias o del poder, es la búsqueda infatigable de cómo satisfacer sus necesidades económicas, es la lucha contra la escasez. Por ello, los bienes adquieren el carácter de mercancía para el cambio. Nace así el comercio, cuya primera forma es el trueque de productos abundantes por otros que escasean.

Los egipcios fueron productores y consumidores de sus productos; los fenicios, limitados por el espacio geográfico, se convierten en comerciantes marítimos por necesidad. Sin embargo, es la economía de Atenas la que monopoliza el tráfico de mercancías en el Mediterráneo oriental desarrollando a la par un importante comercio interior donde el comerciante vende sus productos por la calle, en festivales o en ferias.

El comerciante tiene pues un objetivo, su mensaje tiene una finalidad: vender sus productos y atraer a la clientela. Y, para ello vocea su mercancía en el mercado o por las calles empleando su voz y su elocuencia, utiliza emblemas y se sirve de la escritura en los alba y en los libelli ${ }^{3}$. Asimismo, utiliza señales como elemento localizador de una actividad mercantil determinada; a través del simbolismo el hombre puede encontrar el lugar que busca ${ }^{4}$. Las enseñas representan simbólicamente el producto que el comerciante ofrece, el continente para significar el contenido y la mitología como significante.

Durante la Edad Media, Europa sufre una fragmentación tanto económica como política, no así religiosa. La Iglesia unifica Occidente convirtiéndose en una gran fuerza política; los príncipes, por su parte, debido a sus ambiciones dinásticas, realizan grandes esfuerzos por lograr seguidores, es un deseo eminente de conseguir el apoyo popular. El orden económico y social está determinado durante esta época por la preponderancia de la Iglesia.

1 CUTliP, S. M. y CENTER, A. H.: Relaciones Públicas, Madrid, Ed. Rialp, 1972, pp. 35-36.

2 MUÑOZ ALONSO, A. y otros: Opinión Pública y Comunicación Política, Madrid, Ed. Eudema, 1992, p. 23.

3 Un ejemplo de emblema es la corona de hiedra, planta consagrada al dios Baco, que adornaba en Roma las tabernas y tenía, además de un claro contenido mítico y religioso, una función comercial. Por su parte, los «alba» contenían anuncios de venta y alquiler, mientras los «libelli» eran letreros destinados a fijarse en las paredes cumpliendo generalmente el papel de avisos oficiales.

4 En Atenas, por ejemplo, las tabernas se señalaban con una piña colgada de la fachada que recordaba a los toneles cubiertos de resina para impedir que el vino se filtrara entre las duelas. 
Aunque los testimonios escritos son los que describen la realidad social y económica del período medieval, la comunicación oral alcanza su máximo esplendor $^{5}$. La figura del pregonero se institucionaliza convirtiéndose en el instrumento clave al servicio del comercio. Esta institucionalización está íntimamente ligada al proceso de formación de las ciudades y de la burguesía.

También prolifera el uso de enseñas que se utilizan en el burgo feudal o en la ciudad episcopal para identificar una relación de dominio ya sea espiritual o geográfica alrededor del castillo o de la catedral. Los artesanos están desperdigados por las ciudades y con una importante competencia, los vendedores ambulantes. Por este motivo, estos comerciantes se van a agrupar en gremios, localizados en barrios o calles y plazas determinadas que por asociación propia adquieren la denominación de los oficios que desempeñan ${ }^{6}$.

Es, por tanto, durante el Medievo central cuando aparece el feudalismo, lo que implica la personalización de las relaciones y el establecimiento de conceptos jerárquicos; la monarquía imbuida de principios teológicos; y el renacimiento urbano con la consolidación de los municipios, caracterizados por una nueva ideología basada en una cierta libertad de espíritu y un cierto relativismo.

La Baja Edad Media representa, por su parte, el declive de la teocracia pontificia y la aparición del rigor de Lutero y Calvino, lo que significa el nacimiento de nuevas concepciones políticas, que en su germen darán lugar posteriormente al nacimiento del capitalismo. Es en esta época en la que comienza a definirse el concepto moderno de nación. Ahora, el pueblo toma conciencia de unidad, de grupo con un estilo de vida y con su propia personalidad. De una sociedad inmovilista aparece la nueva cultura urbana, burguesa, capitalista y laica.

Precisamente, en este espíritu capitalista es donde se asientan los orígenes de los actuales instrumentos de comunicación ligados al desarrollo de la burguesía occidental, que les irá dando los elementos necesarios que hoy los definen e, igualmente, la capacidad de acción social, política y económica que los caracteriza.

Entre los siglos XV y XVI, el proceso comunicativo humano presenta un salto a una etapa superior al igual que el siglo XX que alterará sustancialmente los sistemas y fórmulas de comunicación, bajo diferentes series de factores y causas. La imprenta de tipos móviles, lograda por Gutenberg, es el motivo principal de las transformaciones que va a vivir Europa durante la Edad Moderna, ya que gracias a ella el desarrollo del flujo informativo va a ser cada vez más importante y va a alcanzar mayor difusión. En las dos últimas décadas del siglo XIX, siglo del

5 PIZARroso, A.: Historia de la Propaganda, Madrid, De. Eudema, 1993, pp. 62-68.

6 Madrid, en la actualidad, aún conserva lugares en su casco antiguo en los que prevalece el nombre de estos artesanos que se agruparon y trabajaron allí como, por ejemplo, las calles de Latoneros, Cuchilleros, Tintoreros, Bordadores y plazas como la de Herradores o de la Cebada. 
liberalismo, la publicidad era el proceso de comunicación persuasivo más importante; sin embargo, el consumidor compraba una marca, el anunciante distribuía y ofrecía un producto.

La Rusia soviética, la Alemania nazi y la Italia fascista son los tres ejemplos clásicos de un sistema de gobierno totalitario que se refleja en las formas de proceder comunicacionales. Todos los medios de comunicación están al servicio del Partido, ya sea el bolchevique o el partido nazi, porque sus objetivos son los fines del Estado y, en definitiva, de la sociedad. La radio y el cine durante la segunda guerra mundial son los instrumentos propagandísticos en ambos bandos utilizados que en la anterior guerra no se conocían como canales de difusión de ideas.

Finalizada la guerra, las democracias occidentales sustituyen la propaganda por la información dando paso a las actuales administraciones comunicativas que contarán con un instrumento fundamental, la televisión, un arma formidable de persuasión y un instrumento político de primera magnitud. La comunicación política comienza a utilizar, a partir de 1945, técnicas de la comunicación comercial y corporativa, en busca de una mayor eficacia en los mensajes que ha de transmitir en las pugnas electorales o en la organización de cualquier campaña. El régimen democrático debe consolidarse utilizando técnicas y estrategias informativas de consenso.

\section{Comunicación política y Comunicación empresarial: coincidencias persuasivas.}

Tanto la comunicación empresarial como la comunicación política se caracterizan por la intención manifiesta de sus fuentes de modificar la conducta del receptor en algún sentido, ya sea induciendo al consumo o estimulando la participación política, es decir, conseguir que compre un producto o marca, logrando su voto para un partido político o generando un clima de confianza hacia un dirigente político o una institución. Ambos sistemas de comunicación, por tanto, tienen un fin predeterminado con anterioridad: obtener un cambio de actitudes deliberadamente ${ }^{7}$.

Esta búsqueda de efectos en la transmisión de significados aporta una característica al concepto general de comunicación como factor humano y social, nos referimos a la persuasión, entendida como un proceso transaccional compuesto de una clasificación, una selección y una distribución cognoscitiva de símbolos, de modo que se ayuda al otro a deducir de su propia experiencia un significado o una respuesta similar a la que la fuente intenta dar $^{8}$.

7 PETTY, R.E.; y CACIOPPO, J.T.: Communication and Persuation: centrla and peripherical routes to attitude change, Nueva York, Springer, 1986.

8 ROSS, E.S.: Persuasión. Comunicación y relaciones interpersonales, Méjico, Trillas, 1978, p. 93. 
Para ello, tanto el dirigente político como empresarial se ha valido a lo largo de la historia del arte y la ciencia de la Retórica, constituida por la sistematización y explicitación del conjunto de instrucciones o reglas que permiten la construcción de discursos que son codificados para influir persuasivamente en el receptor'. Concepto, el de persuasión, que de acuerdo con Aristóteles, tendría un doble asentamiento: emocional y racional. Esto implica que el receptor, el hombre en la plaza pública, no se define solamente como racional sino en virtud de su complejidad, lo que significa elaborar un mensaje en toda su integridad y de la manera adecuada atendiendo a sus peculiaridades y tratarlo en todas sus posibilidades, es decir, como ser que piense, que siente, que quiere, que actúa en conveniencia o por interés, que no hace lo que parece lógico que debía hacer.

El emisor admite que debe persuadir al receptor para conseguir sus objetivos, lo que implica que debe aceptar la situación de éste, constatación de ineludible utilidad en el análisis de los procedimientos persuasivos de la comunicación política y empresarial. Candidatos y directivos, marcas y productos dependen del público objetivo, si el receptor no le es propicio, su proyecto fracasa. Habilidades personales y retóricas son la clave para persuadir a los receptores del mensaje ${ }^{10}$.

Como técnicas generales de persuasión, tanto en el área empresarial como político, podemos determinar las siguientes ${ }^{11}$ :

- Apelación a los sentimientos;

- Simplificación del mensaje;

- Desfiguración del sentido original de la información;

- Repetición de temas e ideas adecuados a diferentes públicos;

- Explotación del contagio psíquico; y

- Apoyo en las actitudes preexistentes.

La comunicación empresarial y la comunicación política son procesos eficaces cuando su argumentación se fundamenta en las necesidades de los ciudadanos, ya sean éstas de carácter económico o social, así como cuando en ambos sistemas el mensaje considere los sentimientos del público objetivo. Si ambas condiciones se cumplen, el resultado del proceso será óptimo, lo cual significa que aquellos objetivos previamente propuestos se han alcanzado eficazmente.

No obstante, la forma de apelar a los sentimientos es lo que diferencia a estos procesos comunicativos. La comunicación política se apoya en los sentimientos de identificación social, histórica, política, racial o étnica, así como en la

9 AlbadAlejO, T.: Retórica, Madrid, 1989.

10 REY, J.: Los juegos de los políticos. Teoría General de la Información y Comunicación política, Madrid, Tecnos, p. 52

11 ROIZ, M.: Técnicas modernas de persuasión, Madrid, Ed. Eudema Universidad, 1994, p. 50. 
defensa de intereses nacionales y de grupos sociales, estas técnicas también se han empleado con éxito en períodos de crisis y malestar social.

Lutero, por ejemplo, elaboraba su sermón según los intereses e ilusiones de los fieles allí reunidos, sus pláticas eran mensajes con un objetivo previamente determinado: difundir las ideas de la Reforma y crear adeptos a ella. La avalancha de la Reforma, que invade Europa central y nórdica, tropieza, sin embargo, con el baluarte latino, constituido por Francia y las penínsulas ibérica e italiana. La iglesia romana, debido a su centralización, no podía regenerarse más que a través de la reforma de su jerarquía. Éste fue el objetivo del Concilio de Trento. En el último tercio del siglo XVII, la difusión del espíritu tridentino fue asegurada gracias a las órdenes religiosas, cuyos colegios formaron a la élite aristocrática y burguesa de los países católicos; los jesuitas, por ejemplo, utilizaron canales de comunicación como el teatro, que ocupó un lugar preponderante en la pedagogía y el apostolado.

La etapa comprendida entre la primera y la segunda guerra mundial, es decir, el período de entreguerras, se caracteriza por la desestabilización social europea a lo cual se suma la gran crisis económica de 1929. Este panorama de inseguridad social y económica generó el clima adecuado para el nacimiento del sistema político totalitario, modelo en el que la explotación de los sentimientos del receptor se constituye como una de las técnicas fundamentales para ejercer la persuasión de las masas. La omisión de informaciones, la enfatización de mensajes seleccionados previamente y la elaboración de argumentos emotivos, principales técnicas persuasivas del totalitarismo, debido a su éxito, continúa aplicándose durante la segunda guerra mundial por las potencias del Eje.

Especial interés para el nacionalsocialismo tuvo la exaltación de las emociones, sentimientos y necesidades más primarias como la seguridad, dependencia del grupo o la autoestima. Pero al mismo tiempo supieron elevar a necesidades aquéllas de tipo estético como el orden, la armonía, la belleza clásica, la uniformidad o el ritmo; necesidades que suponen respuestas emocionales casi paulovianas. La estética nacionalsocialista, a través de sus emblemas, símbolos y manifestaciones multitudinarias, logró crear un sentimiento de identidad tribal, dotado de una irresistible persuasión a la que contribuyeron armas fundamentales como la radio, la prensa y las concentraciones de masas.

Respecto al objetivo de la comunicación empresarial, es el posicionamiento en el mercado y en la mente del consumidor de los productos o de la empresa como tal, recurriendo para ello a la identificación de la oferta con el prestigio social de sus públicos o con cualquier otra necesidad, es decir, el receptor, en la comunicación empresarial al igual que en la política desactiva su pensamiento lógico y se rige por el pensamiento asociativo, no actúa por argumentación, sino por transferencia arbitraria. 
La vía emotiva pretende seducir, atraer al sujeto mediante la fascinación de las imágenes espectaculares que funcionan a modo de argumento ${ }^{12}$. Los carteles publicitarios son un ejemplo de apelación a los sentimientos, al igual que la función de elección de la marca que genera en el individuo la satisfacción de compra. La comunicación empresarial, y, en particular, su forma comercial, cuya principal técnica es la publicidad de producto o marca se dirige preferentemente hacia el nivel subconsciente mediante el estímulo de los deseos reprimidos.

A finales del siglo XIX, los fabricantes de medicamentos invaden el mercado con nuevas técnicas de comunicación persuasiva, no obstante, continúan utilizando el cartel como medio de difusión de sus mercancías. Numerosos artistas reconocidos estaban dispuestos a pintar carteles que se colocarían en las calles, los portarían individuos por las aceras o se colocarían en vallas donde los viajeros de los trenes pudieran verlos. Los poderes del cartel eran, principalmente, su cualidad icónica, su visualidad instantánea, su fuerza llamativa, el predominio de la imagen y del color, y la presentación de un argumento o de una situación, en los que predominaba el factor estético y emocional. Además, promocionan sus medicamentos a través de artículos de uso cotidiano como relojes o encendedores de cigarrillos, en este caso, hablaríamos de una nueva forma de comunicación comercial que complementa a la publicidad ${ }^{13}$, la denominada promoción de venta cuyos objetivos de producto se refieren a conseguir un rápido lanzamiento, un hábito de consumo, un aumento de la frecuencia de compra y una diferenciación del resto de las ofertas.

En las dos últimas décadas del siglo pasado, las sumas invertidas en publicidad de medicamentos habían alcanzado extraordinarias promociones gracias a los ingresos que el fabricante percibía. Los «inventores» de estos remedios patentados fueron los primeros empresarios en reconocer el poder de penetración del mensaje persuasivo, del logotipo que identificaba una marca y del prestigio de la misma, el atractivo de la posición social y la necesidad, así como fueron los pioneros en la venta de imagen antes que de producto. La publicidad era el proceso de comunicación persuasivo más importante; sin embargo, el consumidor en este caso concreto compraba una marca, el anunciante fabricaba, distribuía y ofrecía un producto. Gracias a la marca, el producto o servicio era posible de identificar y, además, se diferenciaba de la competencia.

Estos conjuntos gráficos, que conformaban la etiqueta de producto o del cartel, reunían al mismo tiempo la identidad de la firma o del producto, la información persuasiva acerca del mismo y la publicidad propiamente dicha. Eran

12 REY, J.: Los juegos de los políticos. Teoría General de la Información y Comunicación política, Madrid, Tecnos, p. 58.

13 PENDERGRASR, M.: For God, Country and Coca-Cola, Estados Unidos, Imprint of McMillan Publishing Company, 1993. 
más anuncios que marcas, reclamos que empleaban simultáneamente la emotividad de la imagen y la racionalidad del texto. Cuando la ilustración, la etiqueta o el cartel tenían éxito se convertían en la marca de la casa. Este momento podemos considerarlo como el antecedente inmediato del concepto actual de marca, que surge a partir de la primera mitad del siglo XX, hasta adquirir su autonomía gráfica como signo de identidad. ${ }^{14}$

No obstante, ya señaló Aristóteles la importancia que debe tener para el orador persuasivo conocer las pasiones humanas. Por tanto, es fundamental conocer el público objetivo al que el emisor se dirige, es decir, los distintos caracteres humanos en relación con las emociones. Jóvenes, ancianos, hombres o mujeres maduros representan pasiones diferentes y temperamentos encontrados. Sus intereses y apetencias son asimismo distintos. Los mensajes, por tanto, deben estructurarse en función de los públicos y teniendo en cuenta sus necesidades. Actualmente, los sondeos de opinión son el instrumento fundamental de los políticos para conocer los deseos y apetencias de sus electores así como la investigación de mercado para las empresas.

El modelo político democrático emplea la explotación de los sentimientos también como forma de persuasión. En sus estrategias persuasivas el sensacionalismo informativo y la creación de conflictos, así como el predominio de la imagen, los eslóganes en las campañas electorales, las siglas y los anagramas justifican dicha afirmación. No obstante, el modelo democrático presenta dos grandes áreas que configuran las campañas electorales: la comunicación aparentemente no persuasiva y la aparentemente persuasiva. Las acciones que conforman el primer proceso comunicativo son los artículos e intervenciones, las entrevistas, las conferencias o actos similares, los artículos y reportajes, los artículos editorial en prensa, radio y televisión, las noticias, etcétera. Respecto a las acciones aparentemente persuasivas destacan los mensajes difundidos a través de espacios pagados y gratuitos, los mensajes enviados directamente al electorado, los mensajes difundidos a través de ordenador, vídeos interactivos, los mítines, etcétera. ${ }^{15}$

Por otro lado y según la Teoría psicológica de la Gestalt, cualquier aspecto que afecte o interese a la persona se estructura en su mente de forma simplificada, por lo que se puede captar fácilmente como una totalidad así como adoptar una u otra postura hacia el mensaje transmitido. El contacto práctico aporta nuevos datos que enriquecen esta primera representación y posibilitan la comparación con otras similares. Éste es el proceso normal desde el conocimiento del todo al de las partes. Sin embargo, cuando el desconocimiento es completo o equivocado y la posibilidad de praxis es inexistente, se elaboran opiniones en relación a las

14 COSTA, J.: Imagen Global, Barcelona, Ed. CEAC, S.A., 1987.

15 ARCEO, J.L., HERREROS ARCONADA, M. y otros: Campañas electorales y Publicidad Política en España (1976-1991), Barcelona, ESRP-PPU, 1993, pp. 19-20. 
aportaciones obtenidas de fuentes secundarias. Si a esta fijación de opinión se une la tendencia de claridad y simplificación, las condiciones reales del objeto se distorsionan. Otro procedimiento de la simplificación es el de reducir las alternativas a sólo dos totalmente opuestas y contradictorias.

En el campo semiológico y lingüístico, la enfatización de los aspectos más relevantes y significativos del mensaje, la presentación de una estructura de la situación, hecho o acontecimiento de manera clara y simple, la parcelación de los problemas y sus contenidos, la inclusión de frases o eslóganes que resuman la idea central de la intención persuasiva son los principales procedimientos de simplificación, así como la inclusión de anagramas, siglas, signos no lingüísticos, la imagen de marca, y los elementos sonoros.

Esta técnica de simplificación se ha utilizado con asiduidad a lo largo de la historia. De la reducción de alternativas, como forma de simplificación, se valió la Iglesia. Diferentes disyuntivas se redujeron a sólo dos: Reforma-Contrarreforma, es decir, se presenta una propuesta de estructura simplificada que, además, se asocia con las preocupaciones de la sociedad, con sus creencias y valores. Para ello, utilizan medios de comunicación en los que aparece la idea central en torno a la cual girarán el resto de aspectos. El sermón, las ilustraciones, incluso, la música, son los principales canales, sin olvidar, la educación y los medios escritos como las Obras Apologéticas o las de divulgación, canales, estos últimos, desarrollados por la Iglesia Católica.

Dentro de la técnica de simplificación, el modelo totalitario ofrece argumentos intentando demostrar la división de opiniones, parcelando los problemas y sus contenidos a la vez que recurre a la simplificación expresada en signos no lingüísticos, eslóganes y símbolos gráficos como la cruz gamada o la hoz y el martillo. Los himnos, tanto del propio partido como de los militares, y la enfatización de algún aspecto relevante fueron otros recursos que simplificaban la idea central facilitando así su percepción por parte de los individuos. Elementos heredados por el modelo democrático que igualmente utiliza signos no lingüísticos, gráficos, eslóganes, siglas y anagramas.

Igualmente acontece en la comunicación empresarial, tanto en su forma comercial como corporativa. La persuasión comercial desarrolla formas, principalmente visuales, y contenidos, sobre todo, emotivos que intentan convencer al público de que sus necesidades y deseos pueden satisfacerse a través de una simple oferta comercial. En la actualidad, la investigación motivacional se utiliza para determinar las necesidades de sus potenciales consumidores y la adecuación o inadecuación del producto y la marca a las mismas.

Respecto a la comunicación corporativa, la publicidad de marca es una regla y procedimiento persuasivo de simplificación, ya que a través de ella se presenta al público objetivo una estructura simplificada de la realidad empresarial y del producto, además de reducir, gracias a sus funciones, la posibilidad de elección. 
Por otro lado, la marca puede considerarse como la enfatización de algún aspecto relevante alrededor del cual se organiza todo un sistema de relación.

Las asociaciones que en la mente del consumidor se producen gracias a la marca, como señal de identidad, simplifican la percepción. La identidad corporativa, por su parte, es otro procedimiento persuasivo de simplificar ya que concentra los rasgos físicos en dos elementos básicos, la marca y el logotipo, consiguiendo una identificación visual en la que se resaltan los aspectos más significativos de la cultura empresarial. Desde la perspectiva de la identidad visual o sígnica, es el diseño gráfico el que se ocupa de la concepción, desarrollo y elaboración de los elementos constituyentes de la identidad de la empresa y de ordenación operativa de su aplicación en la práctica.

Desde la perspectiva de la identidad conceptual, es la personalidad cultural de la empresa, la que responde de la problemática de contenido de dicha identidad, entendiéndose por cultura empresarial el conjunto de rasgos o elementos básicos de identidad, como el pensamiento o las ideas por las que comprende lo que es ella y el entorno en que actúa ${ }^{16}$.

La marca actúa como un nombre propio: califica, individualiza y distingue un producto de la totalidad. Es decir, le otorga un nombre y le saca del anonimato. Sin embargo, la marca en su afán de personalizar y diferenciar, va más allá del nombre propio, puesto que atribuye al producto una identidad y una personalidad únicas. El nombre propio admite la homonimia, la marca, por el contrario, no, entre la marca y el producto se establece una identidad excluyente ${ }^{17}$.

Como técnica complementaria de persuasión ideológica de la simplificación nos encontramos con la personalización del adversario. Se trata de cambiar el significado plural por otro simple y único que singularice lo colectivo. Suele aplicarse al miembro más significativo del grupo. Junto a este recurso propagandístico debemos situar la apelación a la amenaza de alguien exterior, procedimiento que permite desviar hacia el adversario los problemas internos del grupo. Este recurso se potencia cuando en lugar de hacerlo sobre las características sociológicas de la organización se hace sobre los rasgos personales y políticos de su dirigente principal.

En el ámbito político, la desvirtuación de la información se utiliza como técnica persuasiva ideológica, su objetivo es el difundir una ideología determinada con el fin de obtener el suficiente poder como para realizar el bien común. Uno de los primeros fines del organismo romano De Propaganda Fide, fue combatir la Reforma y expandir el catolicismo fuera de Europa. Para ello, crearon impor-

16 TEJADA, L., SANZ DE LA TAJADA, L.A., y ECHEVERRÍA, M.A.: La gestión de un programa global de Identidad, Comunicación e Imagen corporativa, Madrid, Editado por Joint Consultores, 1991, pp. 11-14.

17 REY, J.: Palabras para vender, palabras para soñar. Introducción a la redacción publicitaria, Barcelona, Editorial Paidós, 1996. p. 104 
tantes canales de difusión como las misiones y se encargaron de la propagación en las universidades editando biblias políglotas. Durante el absolutismo, podemos hablar de una persuasión cognoscitiva, ya que los medios escritos resaltaban únicamente aquellos datos que consideraba oportuno el Estado exagerando algunos de los detalles más convenientes para su éxito. En el modelo político absolutista, por ejemplo, el Estado planificó una política de control y vigilancia de los periódicos.

Durante la II Guerra Mundial, la propaganda negra estableció una sólida estructura apoyada en la desvirtuación de los mensajes desfigurando los datos sobre los acontecimientos. Posteriormente, el modelo democrático integrará en sus procesos comunicativos esta regla de persuasión, fórmula que recibirá el nombre de desinformación. La característica fundamental de estos mensajes, difundidos a través de las emisoras de radio aliadas, era la de presentarse ante los alemanes como la voz perseguida de los otros alemanes, los enemigos de Hitler. Su objetivo, perturbar el funcionamiento de la sociedad. Los alemanes también instalarán emisoras que, haciéndose pasar por órganos o grupos franceses pacifistas o extremistas, intentaban fomentar el colaboracionismo y las actitudes antibritánicas. La URSS emitía para Alemania, saboteando programas y colocándose en longitudes de onda de emisoras alemanas. Lo mismo hicieron los norteamericanos, a partir de 1945 desde Luxemburgo ${ }^{18}$.

Además cumple otro objetivo: socavar la unidad del grupo u organización adversaria, ya que sirve para estimular la creación de facciones dentro del mismo, o bien para estimular las deserciones, con lo cual se divide al adversario en su mismo espacio organizativo. Los nacionalsocialistas de Hitler, por ejemplo, supieron llevar este principio a sus últimas consecuencias cuando hablaban del judaísmo internacional, al igual que Churchill cuando definía a los sacerdotes católicos como una cuadrilla de curas hostiles al Estado, o los comunistas al hablar de burguesía europea, el estado burgués, la clase explotadora o el imperialismo norteamericano.

Cualquier persona o institución que de algún modo sea crítica con el gobierno, puede ser objeto de campañas sistemáticas de difamación a través de la televisión o de la prensa en la actualidad. Una de las campañas de desprestigio fue la realizada por Fujimori durante los dos primeros años de su Gobierno contra el Congreso y el Poder Judicial. Continuas denuncias de corrupción difundidas por los medios afines y una actitud innecesariamente hostil por parte del presidente, fueron la preparación psicológica para el golpe de estado de 1992, campaña que se tradujo en un apoyo mayoritario de la población peruana, convencida por la propaganda de que "no había otra salida".

18 DURANDÍN, G.: La mentira en la propaganda política y en la publicidad, Barcelona, Ed. Paidós, 1983, p. 130 . 
La información que puede generar impacto, la que se considera más significativa y que desvirtúa el sentido original del acontecimiento está presente tanto en los procesos comunicativos políticos como en los empresariales. Para conseguir esta desfiguración y exageración del mensaje se utilizan códigos diferentes respetándose siempre la simplificación.

La comunicación empresarial utiliza con frecuencia esta regla persuasiva al aprovechar noticias sobre acontecimientos relacionados con el producto o la marca y así manipular algunos detalles del mensaje informativo, incluyendo juicios que desfiguran el sentido original que tienen los hechos. La comunicación corporativa no publicitaria emplea con frecuencia esta regla valiéndose de técnicas como las relaciones con los medios de comunicación, los actos y ferias, el patrocinio o las relaciones institucionales.

Toda persuasión eficaz utiliza en algún grado la repetición de ideas o juicios de valor. No obstante, la aparición de la televisión, y su capacidad para alcanzar a un público masivo dificultó la posibilidad a los emisores de mensajes de construir una imagen adecuada de éste, por lo que no tuvo más remedio que aceptar las investigaciones sociológicas como referente para orientar sus mensajes a distintos públicos objetivo.

Cuando el mensaje va dirigido a diferentes públicos con características sociológicas y psicológicas divergentes, el tema central se codifica en formas expresivas distintas, adaptándose éstas a los niveles, gustos y preferencias de la audiencia. El bombardeo continuo y masivo de la propaganda consigue que algo de la información transmitida quede en la mente del público, por falso que sea su contenido. En cualquier campaña electoral actual, es habitual que el candidato se dirija a primeros votantes, pensionistas, a miembros de una u otra Comunidad Autónoma en el caso español o a grupos sociales con determinados intereses o expectativas, dirigiendo a cada público una promesa adecuada a sus necesidades.

La repetición de palabras clave y frases hechas o eslóganes es constante, sobre todo en las partes del discurso en las que se enfatiza. Se consigue así que la idea fundamental o eje comunicacional, en el campo de la comunicación empresarial, y los argumentos básicos penetren como estribillos en la mente de los receptores. Esto, unido al énfasis en las afirmaciones, la rotundidad sobre lo positivo y verdadero, todo ello siempre colocado en un lugar del mensaje donde cree sorpresa y produzca atención, es otro procedimiento persuasivo empleado por la empresa y la política. El eslogan comercial y político supone lo más relevante del texto, es el remate del discurso. Entre sus funciones principales destacan la de atraer la atención de los receptores uniéndolos y la función de resumir la idea de la campaña ${ }^{19}$.

19 REBOUL, O.: El poder del slogan, Valencia, Fernando Torrers, 1987, pp. 78-ss. 
El eslogan es una frase breve, simple, concisa, brillante y recordable que expresa la ventaja principal del producto y que se repite a lo largo de la campaña publicitaria ya sea ésta de carácter electoral o publicitario. En el primer tercio del siglo XX los norteamericanos utilizan este término para referirse a la frase breve que aparece en los carteles y anuncios de prensa. No obstante, su origen es anterior derivando del gaélico sluagh-ghairm, ${ }^{20}$ que en la lengua de la vieja Escocia significaba la consigna que usaban los antiguos clanes para avisarse y agruparse en caso de peligro exterior. En torno al siglo XVI, pasa del gaélico al inglés, lengua en la que, en el siglo XIX, adquiere el significado de consigna electoral y también el de divisa de un partido político.

En los años 30, el término eslogan regresa de nuevo a Europa coincidiendo con el auge de los movimientos totalitarios adquiriendo cierto carácter peyorativo, posteriormente, el término será utilizado sólo por el ámbito comercial y publicitario. En la actualidad, tanto partidos políticos, al incorporar técnicas y formas de comunicación publicitarias a sus planificaciones estratégicas, como la comunicación empresarial, utilizan el término eslogan indistintamente.

El eslogan es un procedimiento común en la comunicación política y empresarial. Expresa la ventaja competitiva del producto y se repite durante la campaña publicitaria ya sea ésta de un candidato político o de una marca. Un eslogan es el resultado del análisis de las características del estudio del posicionamiento y de la investigación de los frenos y motivaciones del "producto" publicitario, porque la campaña electoral, en definitiva, es una campaña publicitaria.

Esta promesa seleccionada, no obstante, no es característica únicamente del sistema democrático, Hitler ya utilizó este modelo de mensaje determinado por el grupo social al que fuera dirigido en la Alemania de 1931. Hitler no se privó de prometer a los obreros aumento de sueldo; a los empresarios, garantías de que mantendrían sus beneficios; a los campesinos, el aumento de precios para sus productos; a los ciudadanos en general, la seguridad de que los productos alimenticios serían más baratos, etcétera. ${ }^{21}$

La propaganda leninista, cuyos temas centrales giraban en torno a la creación de un nuevo hombre, la formación de un Estado fuertemente centralizado y la amenaza socialista, se convirtió en repetitiva hasta el extremo de generar en la sociedad soviética un efecto inhibidor. Como instrumentos que favorecieran la repetición empleó la consigna, expresada a través del eslogan, y la prensa que se centraba en discusiones políticas.

20 REY, J.: Palabras para vender, palabras para soñar. Introducción a la redacción publicitaria, Barcelona, Editorial Paidós, 1996. p. 112

21 TCHAKHOtine, S.: Le viol des foules par la Propagande Politique, Gallimard, París, 1952, p.361. 
El modelo democrático, sin embargo, determina tres tipos de ejes comunicacionales: aquellos basados en la doctrina que ejercen gran influencia sobre el electorado militante; los basados en problemas sociales, económicos y políticos de actualidad $\mathrm{y}$, por último, los ejes comunicacionales centrados en el candidato o líder del partido.

Si la penetración del mensaje, las ideas y los juicios de valor centrales se adentran, de forma simultánea, en los distintos ámbitos produciéndose, a su vez, una discusión en el espacio público, el proceso de comunicación que se ha establecido es eficaz. No obstante, debemos señalar que dentro de un mismo grupo, los individuos son altamente sensibles a las reacciones de los demás componentes, sobre todo, en cuestiones controvertidas, lo que da lugar a un contagio psíquico que puede acentuarse gracias a los medios de comunicación de masas, en particular de la radio y la televisión, así como por la utilización de determinadas formas expresivas como las canciones, los himnos y la música.

Tanto en la comunicación empresarial como política, los individuos pueden sentirse atraídos por los modelos personales, el estilo y las actuaciones de determinados dirigentes o personas de cierto prestigio social contagiándoles sus actitudes de una forma principalmente emocional e irracional. En las últimas campañas electorales celebradas en España, por ejemplo, personajes populares, como Antonio Banderas o Norma Duval, participaron a favor de diferentes partidos.

En cuanto a la regla persuasiva de contagio psicológico de los receptores, cabe destacar las manifestaciones colectivas en cualquiera de sus formas, desfiles, mítines, concentraciones y, sobre todo, cuando van acompañadas de un discurso, de la entrega de pasquines y de símbolos de identificación como banderas, estandartes o emblemas; acciones que generan estados de fascinación colectiva.

Hitler es un ejemplo, ya que fundamenta el nazismo en los principios generales de la persuasión ideológica, llegando a conseguir una sociedad uniforme en la que se conjugaron para ello todas las reglas y procedimientos expuestos hasta el momento, además del empleo de estereotipos, la utilización de la mentira, la repetición de palabras claves y frases hechas en sus discursos, las afirmaciones rotundas según iba avanzando la exposición, la apelación a la amenaza exterior y la individualización; técnicas que tanto Lenin como Mussolini emplearon, y el nazismo perfeccionó.

Para justificar el procedimiento del contagio psíquico, no obstante, podemos remontarnos a siglos y modelos anteriores. En el siglo XVII, el absolutismo es el modelo político imperante en Europa y el prestigio del monarca, el estilo propagandístico habitual. El poder se sitúa en el rey quien estará auxiliado por una serie de secretarios y consejeros. Sin embargo, las tensiones, en unos países por cuestiones fiscales, en otros, por razones del campesinado, provocaron revueltas significativas y eficaces en cuanto a la movilización de los estratos sociales de aquella época. Estas revueltas alertaron a las monarquías que establecieron siste- 
mas de control informativo, aunque la prensa clandestina continuó existiendo. Habrá que esperar todavía un siglo para que el Antiguo Régimen ceda sus poderes al modelo político liberal.

Respecto al modelo democrático, cabe destacar que aunque el voto sea el resultado de un acto voluntario individual, lo cierto, es que la persona, en cuanto ser social, encuentra parte de su identificación en cuanto sabe que comparte con otros individuos posiciones políticas idénticas o aproximadas; el individuo se identifica de manera fragmentada, extraída de la experiencia cotidiana, de sus relaciones con los demás y le sirve para confrontar su posición con la de otros, al mismo tiempo que utiliza al grupo para explicar y justificar su propio comportamiento social ${ }^{22}$.

Respecto al contagio psíquico, como procedimiento persuasivo, la comunicación empresarial utiliza gran variedad de formatos para transmitir sus mensajes, desde el anuncio, hasta la identidad visual, las conferencias de prensa, el buzón de sugerencias, etcétera, así como a personalidades públicas, personajes famosos que contagian sus supuestas preferencias al público, generándose así todo un clima de confianza y credibilidad. Los medios de comunicación de masas, sobre todo la radio y la televisión, han sido los canales que más han amplificado el contagio psicológico e, incluso, lo han hecho más atractivo.

La última de las técnicas persuasivas comunes tanto en el área empresarial como político a lo largo de la historia es el apoyo en las actitudes preexistentes. Las actitudes describen las evaluaciones cognitivas permanentes, favorables o desfavorables, sentimientos emocionales y tendencias de acción de una persona hacia algún objeto o idea. La tendencia del individuo en el sistema democrático a rechazar u oponerse al cambio político a medida que avanza en la edad ha sido comprobada en numerosas investigaciones. Por el contrario, el electorado joven es el más predispuesto al cambio. Esta afirmación explica la persistencia de los adultos en su comportamiento electoral basado en su mayor experiencia política. Mientras, que la juventud representa un factor causal determinante de los cambios de opinión, en la creación de nuevas actitudes y en las tendencias de voto ${ }^{23}$.

No obstante, tanto la iglesia católica como la reformista recurrieron también a esta técnica persuasiva, aunque, como es lógico, debido al escaso desarrollo tecnológico de los medios de comunicación no consiguieron llegar a la globalidad geográfica y demográfica de los estados de forma inmediata. El Decálogo luterano, por ejemplo, congregaba, actitudes ya existentes en la sociedad, la práctica religiosa obligatoria favoreció la repetición de estas ideas; mientras temas referentes a los sacramentos, la compurgación o el pecado original fueron las creencias

22 HERREROS ARCONADA, M.: Teoría y Técnica de la propaganda electoral (formas publicitarias), ESRP.PPU. Colección Comunicación y Relaciones Públicas, Barcelona, 1989. p.267.

23 Idem. p.273. 
en las que se fundamentaron los sentimientos más próximos al reconocimiento de la existencia de otro mundo, el temor al castigo, el poder de seres superiores y la resuperación de una moral religiosa. Estas reglas y procedimientos se irán perfeccionando a la par que avanza la sociedad.

En la esfera empresarial, el apoyo en las actitudes preexistentes se fundamenta en la conducta y el aprendizaje que la sociedad adquiere, creencias y actitudes que influyen, a su vez, su comportamiento de compra. Para una empresa es preferible modificar su producto, tangible o intangible, para que encaje con las actitudes preexistentes del público objetivo, que cambiar las actitudes del mismo, a excepción de que el coste de cambiar dichas actitudes merezca la pena pagarse.

Coca- Cola, por ejemplo, en 1985, asediada por la competencia de Pepsi, bebida más dulce, decidió, reemplazar su antigua fórmula con una variante más dulce, denominada New Coke. El lanzamiento del nuevo producto provocó el rechazo del consumidor en su conjunto, los investigadores habían tenido en cuenta el sabor, pero no el apego emocional que el consumidor sentía por la Coca-Cola clásica. Escribían cartas acaloradas, protestas formales, e incluso amenazas de denuncias en los juzgados, todo ello a fin de recuperar el sabor único. Diez semanas más tarde, la empresa retiró el nuevo producto y devolvió a las tiendas la antigua fórmula ${ }^{24}$.

No obstante, Asa Candler, copropietario de la marca Coca-Cola en 1891, es un ejemplo de cambio de las actitudes preexistentes, en este caso sumando publicidad y transparencia informativa. En la mencionada fecha, el periódico Atlanta Constitution publicaba una noticia en la que afirmaba que el producto fomentaba el hábito a la cocaína, ya que uno de los ingredientes con los que se elaboraba era ésta. Candler responde a través de un anuncio en el que invita a los ciudadanos a demostrar la posible adicción. Seguidamente, facilita los datos respecto a los gramos necesarios de hojas de coca por cada cuatro litros de la bebida; un vaso de Coca-Cola no tenía más que una centésima de gramo $^{25}$. Pero, éste no es el primer cambio de actitud de la sociedad norteamericana, Coca-Cola nace como un medicamento para convertirse en pocos años en un refresco.

La publicidad, tanto de producto como de la marca o de la empresa, los sistemas de comunicación interna o externa establecidos, el diseño visual o las relaciones que la institución u organización mantiene, son mensajes dirigidos a un público objetivo con unas características diferentes. De este modo, es necesario adecuar la selección de los temas fundamentales a las correspondientes acciones, la codificación de éstos de forma sencilla y clara adaptada a las características técnicas del medio elegido y a la lingüística de los públicos determinados con

24 KOTLER, P.: Dirección de Marketing, Edición del Milenio, Prentice Hall, Madrid, 2000, p. 353.

25 PENDERGRASR, M.: For God, Country and Coca-Cola, Estados Unidos, Imprint of McMillan Publishing Company, 1993. 
anterioridad. Así, simultáneamente el mensaje penetra en diferentes ámbitos ya sea el hogar, el lugar de trabajo o los espacios de ocio.

En definitiva, y a modo de conclusión, podríamos aducir, en primer lugar, que la comunicación empresarial y la comunicación política son formas principalmente colectivas, aunque utilicen también formas de comunicación interpersonal; en segundo lugar, su mensaje estriba en la tenencia de un objetivo manipulador de la opinión en beneficio de su tesis; en tercer lugar, se basan en la persuasión para la construcción del mensaje, al que atribuyen una eficacia; por último, ambas, política y empresa, actúan sobre el inconsciente para provocar la formación de actitudes y juicios.

Respecto a las principales diferencias se centran en la intención, en el objetivo que persiguen; la política busca influenciar en el cambio de las actitudes fundamentales de los hombres mientras que la comunicación empresarial pretende vender.

No obstante, la incorporación de técnicas comerciales y corporativas a la política ha conferido a ésta cierto carácter novedoso haciéndola más dirigible al emplear procedimientos con los que el individuo se encuentra ciertamente familiarizado ${ }^{26}$. Un claro ejemplo de lo expuesto, son las campañas electorales de los Estados Unidos. Las estrategias planteadas son una simbiosis de técnicas y estilos desarrollados en primer término por el área empresarial americano y asimilado después por la esfera política ${ }^{27}$ que adopta formas comerciales y corporativas en el momento en que no existe diferencia entre los competidores, lo que implica la necesidad de inventarlas. La política se convierte entonces en un producto que se publicita en la sociedad de consumo, aunque las estructuras emocionales del público objetivo de la comunicación política se refieren tan sólo al comportamiento político, afirmación que diferencia un tipo de comunicación de otro ${ }^{28}$.

El proceso comunicativo de una campaña, ya sea empresarial o política, culmina con la definición de la estrategia de medios. Si para definir la estrategia de las líneas de comunicación es necesario partir del conocimiento de las características del público objetivo determinado, de igual manera se actúa al seleccionar y establecer los medios a través de los cuales se han de difundir los mensajes. La estrategia de medios consiste en la formulación de una serie de normas y directrices encaminadas a conseguir la selección y el empleo de los distintos elementos difusores de la campaña en relación al logro de los objetivos planteados.

Los medios primitivos empleados fueron las obras literarias, los triunfos bélicos, las monedas, las estatuas, los carteles y los medios de información pública

26 HERREROS ARCONADA, M.: Teoría y Técnica de la Propaganda Electoral (Formas Publicitarias), Barcelona, Ed. ESRP-PPU, 1989.

27 DOMENACH, J.M.: Propaganda política, Barcelona, Ed. 62, 1963, p. 16.

28 MARINI, M.: Aspetti Psicologici della communicazione e de la propaganda política, Revista Communicazioni Sociali, n 2, 1979, pp. 38-ss. 
de la época, entre otros. Casi todos, adaptados, eso sí, a los tiempos presentes, siguen teniendo vigencia, aunque no con la misma importancia. Hoy en día, la tradicional manera de hacer se ve transformada por la incorporación de una nueva y poderosa herramienta llamada televisión así como por las nuevas tecnologías, sin excluir a los demás medios de comunicación de masas como la prensa o la radio ${ }^{29}$.

Sin embargo, la comunicación interpersonal no debemos ignorarla, ya que en este proceso existen barreras de tipo social y mental que intervienen como filtro que impide llegar a la comprensión óptima de los mensajes percibidos. La imagen propia, la imagen del otro, el ámbito de comunicación y los sentimientos son barreras, ruidos que se interponen, con frecuencia, entre las personas. Los procesos de comunicación interpersonal, empresarial o política, entendidos como estrategias de comunicación, deben llevar a una supresión de estos obstáculos y a la consecución de una comunicación eficaz ${ }^{30}$.

\section{Bibliografía:}

- AlBADAlEJO, T.: Retórica, Madrid, 1989.

- ARCEO, J.L., Herreros Arconada, M. y otros: Campañas electorales y Publicidad Política en España (1976-1991), Barcelona, ESRP-PPU, 1993, pp. 19-20.

- COSTA, J.: Imagen Global, Barcelona, Ed. CEAC, S.A., 1987.

- CUTLIP, S. M. y CENTER, A. H.: Relaciones Públicas, Madrid, Ed. Rialp, 1972, pp. 35-36. Davara, F.J.: Estrategias de Comunicación, Madrid, Dossat 2000, 1994, pp.138-142.

- DOMENACH, J.M.: Propaganda política, Barcelona, Ed. 62, 1963, p. 16.

- DURANDÍN, G.: La mentira en la propaganda política y en la publicidad, Barcelona, Ed. Paidós, 1983, p. 130.

- HERREROS ARCONADA, M.: Teoría y Técnica de la propaganda electoral (formas publicitarias), ESRP.PPU. Colección Comunicación y Relaciones Públicas, Barcelona, 1989. p.267

- HERREROS ARCONADA, M.: Op. Cit. p.273.

- KOTLER, P.: Dirección de Marketing, Edición del Milenio, Prentice Hall, Madrid, 2000, p. 353.

- MARINI, M.: Aspetti Psicologici della communicazione e de la propaganda política, Revista Communicazioni Sociali, no 2, 1979, pp. 38-ss.

- MUÑOZ ALONSO, A. y otros: Opinión Pública y Comunicación Política, Madrid, Ed. Eudema, 1992, p. 23.

29 HERREROS ARCONADA, M.: Teoría y Técnica de la Propaganda electoral (Formas publicitarias), Barcelona, Ed. ESRP-PPU , 1989.

30 DAVARA, F.J.: Estrategias de Comunicación, Madrid, Dossat 2000, 1994, pp.138-142. 
- PENDERGRASR, M.: For God, Country and Coca-Cola, Estados Unidos, Imprint of McMillan Publishing Company, 1993.

- PIZARROSO, A.: Historia de la Propaganda, Madrid, De. Eudema, 1993, pp. 62-68.

- PETTY, R.E.; y CACIOPPO, J.T.: Communication and Persuation: centrla and peripherical routes to attitude change, Nueva York, Springer, 1986.

- REBOUL, O.: El poder del slogan, Valencia, Fernando Torrers, 1987, pp. 78ss. Rey, J.: Los juegos de los políticos. Teoría General de la Información y Comunicación política, Madrid, Tecnos, p. 52

- REY, J.: Op. cit. p. 58.

- REY, J.: Palabras para vender, palabras para soñar. Introducción a la redacción publicitaria, Barcelona, Editorial Paidós, 1996. p. 104

- REY, J.: Op. cit. 112

- ROIZ, M.: Técnicas modernas de persuasión, Madrid, Ed. Eudema Universidad, 1994, p. 50.

- ROSS, E.S.: Persuasión. Comunicación y relaciones interpersonales, Méjico, Trillas, 1978, p. 93.

- TCHAKHOtine, S.: Le viol des foules par la Propagande Politique, Gallimard, París, 1952, p.361.

- TEJADA, L., SANZ DE LA TAJADA, L.A., y ECHEVERRÍA, M.A.: La gestión de un programa global de Identidad, Comunicación e Imagen corporativa, Madrid, Editado por Joint Consultores, 1991, pp. 11-14. 